\title{
Regla de predicción clínica para indicación de TAC antes de la punción lumbar ante sospecha de meningitis
}

Hasbun $\mathbf{R}$ et al.Computed tomography of the head before lumbar puncture in adults with suspected meningitis. N Eng J Med 2001; Vol.345, N24: 1727-33.

\section{Objetivo}

Evaluar si la ausencia de determinadas características clínicas en adultos con sospecha de meningitis aguda puede predecir aquellos que no necesitan una tomografía computada de cerebro (TAC) previa a la punción lumbar (PL).

Diseño

Estudio prospectivo llevado a cabo entre 1995 y 1999.

Lugar

Servicio de emergencias del Hospital de Yale-New Haven, EE.UU. Pacientes

El estudio incluyó 301 pacientes mayores de 16 años que ingresaban a la guardia por sospecha de meningitis, que no hubieran realizado TAC antes del ingreso. La mayoría se presentó con cefalea, fiebre y un nivel de conciencia normal (14 o 15 puntos en la Escala de Glasgow). Sólo 17 \% presentó algún signo focal y 1 paciente tuvo edema de papila.

Test evaluado (Regla de predicción clínica)

Se recogió información al ingreso sobre características sociodemográficas, comorbilidades e inmunocompromiso, examen físico, laboratorio general y examen neurológico.Para este último punto se utilizaron 11 elementos de la Escala modificada de ACV del NIH (ver apéndice al pie), que llevó en promedio 7 minutos realizar. En un $78 \%$ de los casos (235 pacientes) los profesionales decidieron realizar una TAC cerebral antes de la PL. Las TACs fueron realizadas por neurorradiólogos ciegos a los factores de riesgo y conductas, e informadas por dos especialistas en forma independiente. Resultados

El $76 \%$ de los pacientes tomografiados presentaron imágenes normales, y si se incluyen los que tuvieron un resultado anormal pero sin efecto de masa, el porcentaje asciende al $95 \%$.Los pacientes que fueron tomografiados tardaron en promedio 2 horas más que los que no lo fueron hasta la PL (5.3 hs IC $0,9-20,5$ vs 3 hs IC $0,7-$ $14,7 ; p<0,001)$.

A la semana, la mayoría de los pacientes se encontraba sin complicaciones $(78 \%), 51(17 \%)$ presentaron cefalea persistente, 6 $(2 \%)$ foco neurológico y $4(1 \%)$ fallecieron, sólo 1 debido a hernia cerebral. Las características clínicas asociadas a hallazgos anormales en la TAC, se describen en la tabla.

Tabla.Características clínicas asociadas a TAC anormal

\begin{tabular}{l|c|c}
\hline Característica & RR (IC) & Valor de $\mathbf{p}$ \\
\hline Edad $>60$ & $4,3(2,9-6,4)$ & $<0,05$ \\
\hline Inmunocompromiso & $1,8(1,1-2,8)$ & $<0,05$ \\
\hline Antecedentes de enfermedad de SNC & $4,8(3,3-6,9)$ & $<0,05$ \\
\hline Convulsiones la semana previa al ingreso & $3,2(2,1-5)$ & $<0,05$ \\
\hline Nivel de conciencia anormal & $3,3(2,2-4,4)$ & $<0,05$ \\
\hline No responde a 2 preguntas & $3,8(2,5-5,8)$ & $<0,05$ \\
\hline No obedece2 órdenes & $3,9(2,6-5,9)$ & $<0,05$ \\
\hline Alteración de la mirada & $3,2(1,9-5,4)$ & $<0,05$ \\
\hline Alteración del campo visual & $4(2,7-5,9)$ & $<0,05$ \\
\hline Parálisis facial & $4,9(3,8-6,3)$ & $<0,05$ \\
\hline Alteración motora de MS & $4(2,7-5,8)$ & $<0,05$ \\
\hline Alteración motora de Ml & $4,4(3-6,5)$ & $<0,05$ \\
\hline Alteración del lenguaje & $4,3(2,9-6,5)$ & $<0,05$ \\
\hline
\end{tabular}
Alteración del lenguaje $4,3(2,9-6,5)$ $<0,05$

La ausencia de todas las características clínicas antes mencionadas, se asocia a un Valor Predictivo Negativo* del $97 \%$ de padecer anormalidades en la TAC.

\section{Conclusiones}

En adultos con sospecha de meningitis, es posible identificar un subgrupo de bajo riesgo de presentar anormalidades en la TAC, por medio de una regla de predicción clínica, y de este modo poder realizar la PL precozmente.

Fuente de financiamiento: National Research Service Award y Bayer. ra de 2 hs. encontrada en este estudio para iniciar el tratamiento antibiótico en los que fueron tomografiados.

Es destacable que el único paciente que sufrió una hernia cerebral fue detectado mediante la regla de predicción (inmunocompromiso), y de los que fueron tomografiados sólo $5 \%$ presentó efecto de masa.

Como punto en contra, esta regla incluye una lista extensa de signos a evaluar, aunque a los médicos del estudio les llevó sólo 7 minutos en promedio realizarla.

Conclusión del comentador: La presente regla parece sencilla y factible de aplicar en la práctica cotidiana. Sería deseable poder validarla regla en diferentes poblaciones ${ }^{2}$ y de ser posible mediante un estudio multicéntrico, antes de aplicarla masivamente. en los servicios de emergencia en donde tan necesario resulta el manejo rápido y eficiente de los pacientes. Recordemos la demo-

\section{Apéndice. Escala modificada de ACV del NIH}

\begin{tabular}{l|l}
\hline Elemento a evaluar & Puntaje \\
\hline Nivel de conciencia & $0=$ alerta; $1=$ obnubilado; $2=$ no responde \\
\hline Capacidad de respuesta correcta a 2 preguntas consecutivas & $0=$ responde 2 correctas; $1=$ responde 1 correcta; $2=$ no responde a ninguna correcta \\
\hline Capacidad de obedecer 2 órdenes consecutivas & $0=$ obedece 2 correctamente; $1=$ obedece 1 correctamente; $2=$ no obedece ninguna correctamente \\
\hline Evaluación de la mirada & $0=$ normal; $1=$ paresia; $2=$ parálisis \\
\hline Campo visual & $0=$ normal; $1=$ hemianopsia parcial; $2=$ hemianopsia total, $3=$ hemianopsia bilateral \\
\hline Parálisis facial & $0=$ ausente; $1=$ paresia menor; $2=$ parálisis; $3=$ parálisis completa \\
\hline Examen motor de miembro superior & $0=$ normal; $1=$ aducción de la mano antes de 5 segundos; $2=$ mano cae antes de 10 segundos; $3=$ no puede vencer la gravedad; $4=$ parálisis total \\
\hline Examen motor de miembro inferior & $0=$ normal; 1 = ligera caída antes de 5 segundos; $2=$ cáda franca antes de 10 segundos; $3=$ no puede vencer la gravedad; $4=$ parálisis total \\
\hline Ataxia & $0=$ ausente; $1=$ en un miembro; $2=$ en 2 miembros \\
\hline Examen sensorial & $0=$ normal; $1=$ pérdida leve; $2=$ pérdida severa \\
\hline Afasia & $0=$ ausente; $1=$ leve; $2=$ severa; $3=$ mudo \\
\hline Disartria & $0=$ ausente; $1=$ leve; $2=$ severa \\
\hline Disminución de tono de voz & $0=$ ausente; $1=$ leve; $2=$ severa \\
\hline
\end{tabular}

Dra. Victoria Wurcel [ Fellow de Investigación. Unidad de Medicina Familiar y Preventiva. Hospital Italiano de Buenos Aires ]

\section{Referencias}

1. Attia J et al.Does this adult patient have acute meningitis? JAMA 1999;282:175-81.

2.Baker ND et al.The efficacy of routine head computed tomography prior to lumbar puncture.J Emerg Med 1994; 12:597-601. 